\title{
La visión de los estudiantes uruguayos fronterizos sobre la integración cultural en los procesos educativos de la Universidad Federal del Pampa - Campus Yaguarón
}

\author{
A visão dos estudantes uruguaios fronteiriços sobre a integração cultural \\ nos processos educativos da Universidade Federal do Pampa-Campus \\ Jaguarão
}

The vision of the Uruguayan border students about the cultural integration in the education process undertaken by the Federal University of PampaYaguarón Campus

\author{
Lorena Paola Pereira Silva 1 \\ Dr. Clovis da Rolt ${ }^{2}$
}

\begin{abstract}
Resumo
Neste trabalho acadêmico de finalização do Curso de Licenciatura em Pedagogia junto à Universidade Federal do Pampa (UNIPAMPA), a temática abordada consiste na visão de estudantes uruguaios fronteiriços sobre a integração cultural nos processos educativos da UNIPAMPA - Câmpus Jaguarão. Desta temática desprende-se o seguinte problema: na visão dos alunos uruguaios fronteiriços que estudam na UNIPAMPA - Câmpus Jaguarão, a universidade promove a integração cultural em suas práticas educacionais? O estudo tem como objetivo geral investigar as percepções dos alunos uruguaios fronteiriços sobre a integração cultural junto ao Câmpus Jaguarão da UNIPAMPA, além de localizar alguns elementos, fatores ou condicionantes que poderiam favorecer ou desfavorecer tal integração. Cultural. Diversos autores e referências teóricas de corte cultural e educacional foram abordados para aprofundar e compreender melhor a temática em questão. A metodologia deste estudo teve como eixo a abordagem qualitativa, a qual permite olhar para as diferentes percepções dos atores dele participantes. Com este estudo, pode-se refletir acerca da integração cultural em uma instituição educativa de nível superior posicionada dentro de uma perspectiva intercultural.
\end{abstract}

Palavras-chave: Integração cultural; Interculturalidade; Unipampa; Alunos uruguaios fronteiriços.

\begin{abstract}
Uruguayan border students about the cultural integration in the education process undertaken by the Federal University of Pampa-Yaguarón Campus. It is from this subject that the following problematic situation arises : "In the view of these Uruguayan border students who study at Unipampa University in the city of Yaguarón (Brasil), does the University promote cultural integration in its educational practice?. Thus far, it is a general

\footnotetext{
${ }^{1}$ Universidade Federal do Pampa; Unipampa: Jaguarão, Rio Grande do Sul. Brasil. lore.p.s@ @otmail.com

${ }^{2}$ Doutor em Ciências Sociais; Universidade Federal do Pampa; Campus Jaguarão, Rio Grande do Sul, Brasil. cdarolt@hotmail.com
} 
objective to research these students' perceptions with regard to whether or not the Federal University of PampaYaguarón Campus promotes cultural integration in its educational practice and also find some elements, or determining factors that could favour or deter the cultural integration of these Uruguayan border students, alongside the university. Different authors and cultural-educational articles have been consulted for a better and deeper understanding of this issue. The central concept in the method of study has been a qualitative research which allows for knowledge of the different perceptions of the interviewees. It is possible to reflect with this study on the cultural integration in an educational institution placed within an intercultural view.

Keywords: cultural integration, interculturality, Unipampa, Uruguayan border students

\section{Resumen}

En este trabajo académico de finalización del curso de Licenciatura en Pedagogía, la temática abordada es la visión de estudiantes uruguayos fronterizos sobre la integración cultural en los procesos educativos de la Universidad Federal del Pampa - Campus Yaguarón, de la misma se desprende el siguiente problema: "En la visión de los alumnos uruguayos fronterizos que estudian en la Universidad Unipampa en la ciudad de Yaguarón (Brasil), ¿la universidad promueve la integración cultural en sus prácticas educacionales?". Teniendo como objetivo general investigar las percepciones de los alumnos uruguayos fronterizos acerca de si la Universidad Federal del Pampa-Campus Yaguarón promueve en sus prácticas educativas una integración cultural. Así como también localizar algunos elementos, factores o condicionantes que podrían favorecer o desfavorecer la integración cultural de los alumnos uruguayos fronterizos junto a la universidad. Diversos autores y artículos de corte cultural y educacional fueron abordados para profundizar y comprender mejor el tema en cuestión. La metodología de estudio tuvo como eje una investigación cualitativa, la cual permite conocer las diferentes percepciones de los sujetos entrevistados. Con este estudio se puede reflexionar acerca de la integración cultural en una institución educativa posicionada dentro de una perspectiva intercultural.

Palabras-clave: Integración cultural; Interculturalidad; Unipampa; Alumnos uruguayos fronterizos.

\section{Elementos introductorios}

A lo largo de mi trayectoria como alumna del curso de Pedagogía de la Universidad Federal del Pampa ubicada en la ciudad de Yaguarón, RS, Brasil, fueron varias las temáticas referentes al campo de la educación que despertaron mi interés, pero el tema de la diversidad cultural, fue el que más cuestionamientos me planteó. En la condición de ser uruguaya y vivir en la ciudad de Río Branco (Uruguay) mi ingreso en la Unipampa ocurrió mediante un proceso selectivo específico para los llamados "uruguayos fronterizos". Esta condición me trajo muchas vivencias, aprendizajes, conquistas y desafíos, los cuales ciertamente marcaron mi vida para siempre. Pude crear nuevas miradas, sobre cuestiones de naturaleza cultural, pensar y reflexionar sobre diversos temas, entre ellos: noción de frontera, construcción de identidades, integración cultural, que no habrían surgido sin la posibilidad de experimentar la vida en el ámbito de otra cultura. Estas cuestiones, en el ámbito de mi experiencia como académica, me llevaron a un cuestionamiento principal: ¿Existe, de hecho, una integración cultural entre brasileros y uruguayos dentro del contexto académico y de sus procesos educativos?¿Esta supuesta integración realmente se da?¿De qué modo?

Entre diversos temas, uno me llamó especialmente la atención y me hizo reflexionar sobre las cuestiones anteriormente expuestas. Una compañera que ingresó a la Unipampa 
como alumna fronteriza desistió en el primer semestre y me comentó que el motivo de desistir era la dificultad con el idioma portugués. Esa dificultad hacía con que ella hablara español en clase y los compañeros brasileños no la entendieran.

A partir de lo expuesto, puede constatarse que fueron principalmente motivos personales los que me condujeron a la temática que será tratada en este trabajo académico: "la visión de estudiantes uruguayos fronterizos sobre la integración cultural, en los procesos educativos de la Universidad Federal del Pampa - Campus Yaguarón.”

La problemática que envuelve la construcción de este artículo puede ser sintetizada en el siguiente cuestionamiento: “¿En la visión de los alumnos uruguayos fronterizos que estudian en la Universidad Unipampa en la ciudad de Yaguarón (Brasil), la universidad promueve la integración cultural en sus prácticas educacionales?" A partir de este cuestionamiento mayor, se define como objetivo general de este artículo investigar las percepciones de los alumnos uruguayos fronterizos acerca de si la Universidad Federal del Pampa-Campus Yaguarón promueve en sus prácticas educativas, una integración cultural. Se pretende además localizar algunos elementos, factores o condicionantes que podrían favorecer o desfavorecer la integración cultural de los alumnos uruguayos fronterizos junto a la universidad.

La construcción de este artículo está sustentada en un abordaje de investigación cualitativa, que tiene como eje la visión de los actores sociales encuadrados en la categoría "estudiante uruguayo fronterizo". Los referentes teóricos que condujeron los argumentos mencionados, son oriundos de diversos campos del conocimiento, inclusive profesores de la Unipampa, que se unen a través del vector de la cultura como horizonte analítico. A pesar de las diferencias que pueden existir entre ellos, busco, con este artículo, la interlocución y el diálogo, en el sentido de ofrecer una contribución sobre el tema aquí discutido.

\section{Concepto de cultura, identidades y relaciones interculturales}

Hablar de cultura es muy complejo, pues se le ha atribuido muchos significados a lo largo de la historia y este concepto varía según los autores y sus perspectivas teóricas. Machado (2002, p. 18) hace referencia que

ao longo dos anos o termo "cultura" foi se modificando e somente a partir do surgimento do vocábulo inglês culture é que foi estabelecida sua acepção complexa, que abrange conhecimentos, crenças, arte, moral, leis, costumes ou qualquer outra habilidade ou tradição adquiridos pelo homem, tal como a vemos hoje. 

e-ISSN 2016/Atual: 2525-7870 | e-ISSN 2015/2016: 2447-018X

Son muchos los autores que tratan sobre la temática de la cultura. Mello (2011) la conceptualiza no solo como que es adquirida y estable de acuerdo a las tradiciones y padrones de comportamientos, sino que principalmente se transforma, cambia a cada descubrimiento y a cada innovación. La cultura debe ser vivida y exteriorizada, pues no es un proceso individual, sino que es colectivo, simbólico y social, que se transmite de generación a generación y que va evolucionando y transformándose a lo largo del tiempo.

Couto (2012, p. 31) hace un abordaje muy interesante sobre cultura diciendo que

a cultura como uma luta em torno de significados e estes são produzidos por meio da linguagem. Esta, seja falada, escrita, ou materializada em gestos e objetos tem papel importante, não pelo que ela é, senão pelo que faz, pois ela constrói e transmite significados - produz identidades e por conseguinte, diferenças. Estes significados, por sua vez, são sempre contingentes, limitados por situações históricas, políticas e culturais de sua produção. Nestes termos, a linguagem torna-se fundamental para o significado, pois é o meio pelo qual os pensamentos, as idéias e os sentimentos são representados na cultura.

Partiendo de lo mencionado, el lenguaje es un aspecto muy importante cuando se habla de cultura, porque es a partir de esta que le damos el significado a todo lo que sentimos y pensamos, nos permite exteriorizar diferentes maneras de vivir, y también es un medio para comunicarnos con las demás personas, para expresar y compartir valores con diferentes grupos étnicos, sociales y culturales, de diferentes comunidades.

Vivimos en un mundo globalizado caracterizado por complejos cambios en lo social, político, ideológico, económico, religioso y cultural. En la que la globalización conlleva a un contacto más fuerte entre diferentes culturas y reafirma temas como: identidades, diferencias sociales y culturales, teniendo los derechos humanos un rol fundamental.

Para poder entender las identidades nacionales, debemos comprender no solo qué es cultura, sino también como ésta se manifiesta y que efectos produce en la vida de los diferentes grupos. En este sentido Hall (2006, p.108-109) proclama que

a identidade cultural, carrega consigo distintos traços como aqueles ligados à nacionalidade e pertencimento a um local. As identidades culturais não são identificadas com um passado histórico, com o qual elas continuariam a manter certa correspondência, mas sim, com a questão da utilização dos recursos da história, da linguagem e da cultura para a produção daquilo no qual as pessoas se tornam. As identidades têm a ver com como nós temos sido representados e como essa representação afeta a forma como nós podemos representar a nós próprios. Elas têm tanto a ver com a invenção da tradição quanto com a própria tradição.

De acuerdo con Hall (2006), podemos afirmar que las identidades son producidas y transformadas constantemente. A partir de lo expuesto este trabajo académico pretende 
alcanzar un debate muy presente en la actualidad, que es la cuestión de la interculturalidad y los diferentes modos de vivencia contemporánea de la cultura, en lo que se refiere a las formas de contacto, intercambios y mestizaje cultural. Este es un hecho con el cual vivimos cotidianamente en el ámbito de una frontera, donde se produce un encuentro de dos países y, consecuentemente, de dos culturas.

Partiendo de lo anteriormente mencionado este artículo utiliza el término interculturalidad para intentar comprender las relaciones culturales en ese espacio de frontera Río Branco (Uruguay)/Yaguarón (Brasil) con el fin de mirar esa diversidad cultural y esas relaciones marcadas por luchas, poder, semejanzas y diferencias entre los diferentes grupos que la componen. No se puede hablar de interculturalidad sin pensar en cuestiones como identidades y diferencias, así como no se puede tratar de identidades sin pensar en las diferencias, estos dos aspectos están íntimamente relacionados, uno depende del otro. Para reafirmar lo anteriormente mencionado Couto (2012, p. 65) dice "é impossível falar de identidade e de diferença sem falar de língua. Esta, nesse contexto, diz quem o sujeito é e o que ele não é”. En este sentido se puede decir que la lengua reafirma identidades, haciendo una diferenciación entre brasileños y uruguayos. Muchas veces cuando una de estas identidades no es reconocida conlleva a una segregación cultural.

Para Walsh (2001, p. 10-11), a interculturalidade é

\begin{abstract}
um processo dinâmico e permanente de relação, comunicação e aprendizagem entre culturas em condições de respeito, legitimidade mútua, simetria e igualdade. Um intercâmbio que se constrói entre pessoas, conhecimentos, saberes e práticas culturalmente diferentes, buscando desenvolver um novo sentido entre elas na sua diferença. Um espaço de negociação e de tradução onde as desigualdades sociais, econômicas e políticas, e as relações e os conflitos de poder da sociedade não são mantidos ocultos e sim reconhecidos e confrontados. Uma tarefa social e política que interpela o conjunto da sociedade, que parte de práticas e ações sociais concretas e conscientes e tenta criar modos de responsabilidade e solidariedade.
\end{abstract}

Pensar desde una perspectiva intercultural la educación es partir de la relación entre culturas, esto requiere reconocer no solo mi cultura, sino el reconocer y comprender las culturas en contacto. Esto implica no solo una aceptación de las instituciones por recibir estudiantes de diferentes nacionalidades, etnias y culturas, sino que exige que el sistema educativo adopte políticas que promuevan las igualdades de oportunidades, políticas que incluyan las diversidades culturales, que sean más democráticas, que partan del diálogo y la negociación entre los diferentes grupos socioculturales, es lo que Santos denomina de hermenéutica diatópica. 
Trabajar y comprender todos estos conceptos tratados en esta primera sección, constituye un punto muy importante para esta investigación, porque no se puede pensar una perspectiva basada en la interculturalidad, sin tener presentes temas como culturas, identidades y diferencias. Además ésta investigación será realizada en un espacio de frontera Río Branco (Uruguay)/Yaguarón (Brasil) donde existe una hibridación cultural, término usado por unos de los clásicos como es Canclíni, que usa el termino de "hibridación" haciendo referencia a que

se encontrarán ocasionales menciones de los términos sincretismo, mestizaje y otros empleados para designar procesos de hibridación. Prefiero este último porque abarca diversas mezclas interculturales - no sólo las raciales a las que suele limitarse "mestizaje" - y porque permite incluir las formas modernas de hibridación mejor que "sincretismo", fórmula referida casi siempre a fusiones religiosas o de movimientos simbólicos y tradicionales. (CANCLÍNI, 1992, p. 14-15).

Silva (2000, p. 87) complementa la idea anterior diciendo que

não se pode esquecer, entretanto, que a hibridização se dá entre identidades situadas assimetricamente em relação ao poder. Os processos de hibridização analisados pela teoria cultural contemporânea nascem de relações conflituosas entre diferentes grupos nacionais, raciais ou étnicos. Eles estão ligados a histórias de ocupação, colonização e destruição. Trata-se, na maioria dos casos, de uma hibridização forçada.

A partir de lo mencionado por estos autores, reflexionamos sobre ese concepto de interculturalidad que en esta investigación no solo va a surgir de la relación y mezclas culturales, sino también por cuestiones ideológicas y de poder, que ultrapasan las diferentes relaciones entre los grupos y sus identidades.

\section{La idea de frontera y sus especificidades en el ámbito de las ciudades de Río Branco (Uruguay) -Yaguarón (Brasil)}

En este trabajo se pretende definir brevemente qué se entiende por frontera. Para posteriormente tratar sobre las especificidades de esta frontera Río Branco (Uruguay) Yaguarón (Brasil), partiendo del contexto socio-histórico, político, geográfico y cultural en que se encuentra, de los actores sociales (uruguayos y brasileños) y las relaciones que entre estos se producen en este espacio fronterizo.

A lo largo de la historia, han existido diversos factores como ser: guerras, disputas, ambiciones desmesuradas, crisis internas y externas, inflaciones, regímenes militares, que han hecho con que países como Brasil, Uruguay así como otros países de América Latina, 

e-ISSN 2016/Atual: 2525-7870 | e-ISSN 2015/2016: 2447-018X

tuvieran la necesidad de unirse, de establecer lazos de cooperación e integración entre los mismos. La integración comenzó a establecerse mediante una serie de tratados y de acuerdos entre los países involucrados, que no se irán a detallar en este momento, porque lo que se pretende es entender cómo es este espacio de frontera Rio Branco/ Yaguarón actualmente y cómo son las relaciones entre los actores sociales que en ella conviven.

Esta integración tiene repercusiones hasta el día de hoy, como dice Rizzon (2012, p.120-121).

A ponte estabelece um vínculo de aproximação através do trânsito de idas e vindas que ela permite [...] No entanto, mesmo possibilitando o trânsito, pode-se entender o estreitamento proporcionando pela ponte em seus dois sentidos, pois, junto à aproximação, há também um estrangulamento dos caminhos, uma passagem controlada e fiscalizada.

Lo mencionado anteriormente debe ser entendido en base a este nuevo contexto marcado por la globalización y por el capitalismo, que por un lado aproxima a países, continentes y regiones, pero por otro lado, genera individualismo, discriminación y exclusiones de todo tipo, haciendo necesario que se establezcan políticas de integración regional, entre países que, como Uruguay y Brasil comparten fronteras. Como declara Gómez (2011, p. 3),

o processo de globalização em curso afeta a organização econômica social e política do mundo contemporâneo. De forma que, para se pensar o projeto de integração regional pretendido pelo Brasil e Uruguai, torna-se necessário um estudo sistemático do fenômeno da regionalização como constitutivo da globalização que "flexibiliza as fronteiras". Nesta perspectiva, estamos diante de uma nova concepção do conceito de fronteira, em contraposição à idéia de limite e separação, passamos a percebê-la como um espaço de hibridismo e de integração no contexto ideológico do mundo globalizado.

Partiendo de lo expuesto por el autor, hablar de frontera actualmente es pensarla no como algo fijo, como línea o limite que separa territorios y países, sino que el concepto de frontera adquiere nuevos significados. Específicamente sobre la frontera de Rio Branco y Yaguarón que es donde se desarrolla el objeto de este estudio. Couto (2012, p. 49), a partir de su estudio sobre esta frontera, la define como

um espaço multicultural, pois aqui as relações identitárias estão em constante processo de marcação. Não nos referimos a um espaço e tempo qualquer especificamente, referimo-nos aos processos de marcação e produção identitária e cultural que ocorrem na especificidade dessa fronteira. 
Pensar la frontera en estudio, según estos autores, es entenderla como un espacio diferente de los que quieren definir muchas veces los Estados, los gobiernos, pues este no puede ser mirado solo desde una línea divisoria, sino como un espacio híbrido, marcado por las inter-relaciones y demarcación de identidades y culturas. Siendo el concepto de identidad, caracterizada en la primera sección de este trabajo, fundamental para poder entender las relaciones que se establecen en esta frontera. Mazzei (2012, p. 18) en su estudio sobre esta frontera hace referencia al reconocimiento de la "identidad fronteriza" como un valor propio, compartido e intransferible de los vecinos de la frontera.

Podríamos decir, a partir de todo lo abordado en esta sección, que esta frontera es un lugar caracterizado no solo por la movilidad de mercaderías, transportes, y personas, sino también por las relaciones que se producen entre sus habitantes, destacándose entre ellas los matrimonios, lazos sanguíneos, de trabajo, estudio, el convivir con los idiomas (español y portugués), el ser muchas veces, en términos coloquiales “doble chapa” (doble nacionalidad), entre otras, que hace de esta frontera un espacio híbrido, particular y único. A su vez este espacio fronterizo se encuentra interceptado por barreras y trabas que imponen los EstadosNación, que produce ambivalencias, reafirma inestabilidades, conflictos, y demarcación de poder.

\section{4 ¿Qué se entiende por integración culltural?}

Hablar sobre qué se entiende por integración es tener en cuenta lo que dice Londoño (1995 p. 12). Para este autor,

responder a la pregunta qué se integra, cómo se integra y para qué se integra remite a pensar por lo común, limitadamente, que la integración se enmarca en un espacio y un tiempo delimitados y que en ella entran en juego una serie de actores formales: en la mayoría de ocasiones se pasa por alto que la integración como proceso debe ser analizada en el marco de una dinámica que sobrepasa las fronteras nacionales e involucra el encuentro e intercambio entre múltiples sujetos. Nos referimos con ello al proceso de globalización que determina de forma bastante sustancial los procesos de integración y que, de una forma u otra, está definiendo quiénes y para qué se integran.

De lo expresado anteriormente se desprende, que la integración es un proceso que se fue configurando a lo largo de la historia, mediante políticas, tratados y acuerdos que hicieron necesario la integración regional de países, específicamente este trabajo se centrará en la integración cultural.

A partir de lecturas realizadas sobre la temática se puede decir que es a fines del siglo XIX que se generó un fuerte impulso de integración cultural latinoamericana, producto de 

e-ISSN 2016/Atual: 2525-7870 | e-ISSN 2015/2016: 2447-018X

transformaciones políticas, socioeconómicas y culturales. Todo este preámbulo sirvió de base para que en la década de 1990, en un contexto neoliberal, se configure el MERCOSUR (Mercado Común del Sur) referente de integración de los países de América del Sur entre los que se encuentra Brasil y Uruguay, a este bloque primero se le atribuyó un carácter económico y comercial, para posteriormente abordar diferentes aspectos como: sociales, culturales y educacionales. El MERCOSUR cultural (1996) en su protocolo de integración hecho en Fortaleza, establece diferentes artículos donde destaca prioridades para dicha integración, en síntesis en sus artículos del $1^{\circ}$ al $5^{\circ}$ se comprometen a promover la cooperación, coproducción e intercambio, entre instituciones y partes involucradas, a través de políticas, programas y proyectos en común.

En este contexto es que pensamos la integración cultural, en estrecha relación a una integración educacional, como manifiesta el Plano Nacional del Sector Educacional del MERCOSUL (SEM) (2011-2015, p.1) en su visión y misión:

- Ser un espacio regional donde se brinda y garantiza una educación con equidad y calidad, caracterizado por el conocimiento recíproco, la interculturalidad, el respeto a la diversidad, la cooperación solidaria, con valores compartidos que contribuyan al mejoramiento y democratización de los sistemas educativos de la región.

- Conformar un espacio educativo común, a través de la concertación de políticas que articulen la educación con el proceso de integración del MERCOSUR, estimulando la movilidad, el intercambio y la formación de una identidad y ciudadanía regional, con el objeto de lograr una educación de calidad para todos, con atención especial a los sectores más vulnerables en un proceso de desarrollo con justicia social y respeto a la diversidad cultural de los pueblos de la región.

De lo expuesto podemos ver que muchos esfuerzos y progresos se han dado a lo largo de la historia, como por ejemplo los acuerdos establecidos por el MERCOSUR, pero éstos a su vez son muy polémicos, debido a sus avances, estancamientos y retrocesos. Se puede decir que para alcanzar dicha integración cultural y educacional se necesitan políticas que promuevan la cooperación y el intercambio entre sus respectivas instituciones y agentes culturales, esas políticas deben ser entendidas desde la perspectiva de la interculturalidad.

Este artículo parte de una perspectiva intercultural, como sostiene Candau (2008, p. 8), que sea capaz de

promover uma educação para o reconhecimento do "outro", para o diálogo entre os diferentes grupos sociais e culturais. Uma educação para a negociação cultural, que enfrenta os conflitos provocados pela assimetria de poder entre os diferentes grupos socioculturais nas nossas sociedades e é capaz de favorecer a construção de um projeto comum, pelo qual as diferenças sejam dialeticamente integradas. A perspectiva intercultural está orientada à construção de uma sociedade democrática, plural, humana, que articule políticas de igualdade com políticas de identidade. 
En el caso de las fronteras Brasil (Yaguarón) y Uruguay (Rio Branco) esa integración cultual y educacional se la podría mirar desde una perspectiva de la diversidad cultural, manifiesta en las identidades culturales que se expresan a través de diálogos, historias, tradiciones, valores, diferencias y procesos colectivos que reafirman lazos de aproximación, cooperación e intercambios entre los países y ciudadanos. Londoño (1995 p.6-7) trae aspectos interesantes acerca de cómo pensar la integración cultural.

Pensar la integración en un mundo globalizado, en el que las distancias se hacen cada vez más cortas y los lazos parecieran estrecharse, nos remite de entrada a considerar que, hoy más que nunca, las identidades alcanzan un papel protagónico y, por ende, la cultura como elemento integrador, incluso más efectivo que el económico y comercial, adquiere un lugar predominante en la agenda de los procesos de integración en curso. La convicción de que la integración debe despojarse del revestimiento institucional y pragmático que la caracterizaba para vestirse de diversidad y tramas sociales, con el fin de insertarse en el lenguaje y experiencia de los ciudadanos partícipes de los procesos de integración.

Partiendo de lo anteriormente mencionado por Londoño (1995) sobre la importancia de la integración cultural, se puede decir que esta temática es motivo de debate y actualmente existe un fuerte movimiento planteando y articulando diferentes proyectos. A continuación se citarán brevemente algunos ejemplos donde la integración cultural es pensada y articulada desde perspectivas interculturales.

El MERCOSUR (2007, p. 2) en su programa de escuelas interculturales bilingües de frontera promueve un "Modelo de enseñanza común en escuelas de zona de frontera a partir del desarrollo de un programa para la educación intercultural, con énfasis en la enseñanza de las lenguas predominantes en la región”. Esto también está explícito en el estatuto fronterizo (2010), el cual entre los diversos temas que aborda, expone los diferentes proyectos y programas en educación que se están implementando, con el objetivo de promover una integración cultural y educacional en las fronteras.

También se ve latente la integración cultural a través de la UNILA (Universidade Federal da Integração Latino - Americana), localizada en Foz del Iguaçú, Brasil, habilitada por una ley en enero del 2010. Esta universidad está pensada desde una perspectiva intercultural, se caracteriza por ser bilingüe y con un currículo pensado desde y para la integración. Ricobom (2010, p. 7), en su trabajo estudia a esta universidad y hace referencia a cómo es pensada la misma desde la interculturalidad. 
RELACult - Revista Latino-Americana de Estudos em Cultura e Sociedade

Revista Latinoamericana de Estudios en Cultura y Sociedad | Latin American Journal of Studies in Culture and Society

V. 02, Ed. Especial, dezembro, 2016, p. 225-246| periodicos.claec.org e-ISSN 2016/Atual: 2525-7870 | e-ISSN 2015/2016: 2447-018X

O ambiente universitário da Unila não poderá se resumir em um espaço multicultural, apenas de tolerância das diferenças por meio de uma política de reconhecimento, de respeito às individualidades, onde não há interseção cultural [...]. A interculturalidade pressupõe um diálogo onde não há hierarquia entre as diferentes culturas, que não se resume na soma de identidades e sim na construção de valores em comum. Isso deve ser realidade em todos os níveis da instituição, seja nas relações docentes, discentes e administrativas, enfim em todo o complexo de relações que se desenvolvem em uma Instituição de Ensino.

Considerando lo expuesto anteriormente podemos presenciar avances significativos acerca de la temática en estudio, donde se está proyectando una educación que trate la integración cultural, desde la enseñanza primaria hasta la enseñanza superior. De esta forma no solo se estará considerando los intereses de los diferentes países por separado, sino que se enfocaría la educación a partir del contexto en que está inserta, con el objetivo de promover la integración regional en sus diferentes dimensiones.

\title{
5. La singularidad de un espacio fronterizo: Universidad Federal del Pampa (Unipampa) y estudiantes uruguayos fronterizos
}

En esta sección primeramente se hará referencia sobre la Unipampa, para luego focalizar en el ingreso de dichos estudiantes en la universidad.

La Unipampa se encuentra localizada en el estado de Rio Grande del Sur, en una zona de frontera con países como Uruguay y Argentina. Esta facultad cuenta con aproximadamente 12.214 alumnos matriculados en cursos de graduación y 1189 cursando pós- graduación, según el portal (Unipampa, 2016), en los 10 campus en que se encuentra dicha institución. Para conocer que objetivos o el porqué de su surgimiento se consultó al portal de la Universidad Federal del Pampa (UNIPAMPA, 2015).

\begin{abstract}
A Universidade Federal do Pampa foi criada pelo governo federal por meio da lei ${ }^{\circ}$ 11.640 , de 11/01/2008, para minimizar o processo de estagnação econômica onde está inserida, pois a educação viabiliza o desenvolvimento regional, buscando ser um agente da definitiva incorporação da região ao mapa do desenvolvimento do Rio Grande do Sul. A expansão da educação pública superior, com a criação da Universidade Federal do Pampa, além de concretizar um antigo sonho da população, permite que a juventude, ávida de conhecimentos, permaneça em sua região de origem e adquira as informações necessárias para impulsionar o progresso de sua região, no momento em que se forma mão-de-obra qualificada, e aumenta-se a autoestima de seus habitantes, tendo, como consequiência, o surgimento de novas famílias, cujos filhos vislumbrarão opções para que se desenvolvam sociedades cultural e economicamente independentes.
\end{abstract}

A través del portal de la Unipampa, podemos ver que esta facultad surge principalmente por razones económicas, para el desenvolvimiento regional, y para fortalecer la permanencia de los jóvenes en su región. 

e-ISSN 2016/Atual: 2525-7870 | e-ISSN 2015/2016: 2447-018X

El interés de este trabajo es focalizado en la Unipampa ubicada en la ciudad de Yaguarón (Brasil) en la frontera con Rio Branco (Uruguay), específicamente se centrará en el ingreso de "uruguayos fronterizos". El proceso selectivo de los mismos se inició en el año 2011, con el edital 145/2011, el cual especifica las formas de ingreso de esos estudiantes a partir de ítems como las vacantes de alumnos, que para el caso de Yaguarón eran cinco para cada curso (Turismo, Letras, Historia, Pedagogía), también especifica las formas de inscripciones, la documentación necesaria entre otros requisitos.

En el portal de la Unipampa el 21 de octubre del 2011 Aires dice: "O ingresso de fronteiriços favorece o intercâmbio entre os países e fortalece os laços da cultura e a troca de conhecimentos da comunidade discente", complementando las palabras Dilli (2011) afirma que "com as novas formas de ingresso que a UNIPAMPA oferece poderemos abrir ainda mais espaço a todas as culturas e etnias". De lo que se desprende que la Universidad también mira lo cultural, la región, la importancia del intercambio cultural, aunque no manifiesta explícitamente en sus palabras la temática: integración cultural.

La Unipampa además de los edítales sobre el proceso selectivos para fronterizos, se rige por un Decreto $\mathrm{N}^{\circ}$ 5.105. del 14 de junio 2004.

Promulga o acordo entre o Governo da Republica Federativa do Brasil e o Governo da Republica Oriental do Uruguai para Permissão de Residência, Estudos e Trabalho a Nacionais, Fronteiriços Brasileiros e Uruguaios, de 21 de agosto de 2002.

El decreto explicita que fue creado para promover la integración de las fronteras de los países vecinos, para eso promueve el permiso de residencia, estudios y trabajo, centrándose específicamente a partir de artículos, en qué consiste ese documento fronterizo.

Pensar en esa categorización "uruguayo fronterizo", nos remite a una cierta ambivalencia, porque por un lado se es uruguayo, también se es fronterizo y se está en una facultad, en otro país, con otra cultura, pero también existe esa frontera que reafirma identidades y diferencias entre los diversos sujetos. Es interesante lo que Couto (2012) dice sobre los términos "castelhano e brasilero", porque es otra categorización usada en esta frontera, que también reafirma lo expresado anteriormente.

Entendemos que os termos, castelhano e brasilero, são invocados para marcar a diferença entre brasileiros e uruguaios. Isso são formas marcadoras da posição que estes sujeitos ocupam nesta fronteira - diferentes posições de sujeito compõem a identidade da fronteira, marcam as diferenças. Couto (2012, p.56). 
En este trabajo al analizar las percepciones de los alumnos fronterizos uruguayos sobre la temática en estudio, nos permitirá reflexionar sobre las formas de ver y sentirse en la facultad de los mismos, su integración o no, en los procesos educativos y culturales que la facultad debería promover y que es tema cada vez más discutido por la relevancia que tiene para con las sociedades.

\section{Camino Metodológico}

Los autores citados durante todo este artículo son fundamentales para este estudio porque articulan temas que interesan a la temática aquí abordada, permitiendo una mayor comprensión e interpretación de los datos. Las pluralidades de voces de estos autores son importantes como forma de mostrar la amplitud del tema. Permitiendo a partir de los datos que se obtengan, reflejar en el análisis, los diferentes temas tratados en las secciones anteriores.

Este trabajo académico tiene como eje una investigación social de corte cualitativa. Según Minayo (2001, p.21-22),

a pesquisa qualitativa responde as questões muito particulares. Ela se preocupa, nas ciências sociais, com um nível de realidade que não pode ser quantificado. Ou seja, ela trabalha com o universo de significados, motivos, aspirações, crenças, valores e atitudes, o que corresponde a um espaço mais profundo das relações, dos processos e dos fenômenos que não podem ser reduzidos a operacionalização de variáveis.

Para la realización de esta investigación cualitativa se pretende utilizar como técnica para recolectar los datos, la entrevista semi-estructurada, pues permite que los sujetos entrevistados puedan expresar más libremente sus diferentes opiniones acerca del tema en estudio. Fueron pensadas preguntas que contemplaran los objetivos propuestos, estas son: a) ¿Existen o existieron elementos, factores o condicionantes que favorecieron o desfavorecieron tu integración cultural? b) ¿En tu trayectoria académica en la Unipampa, consideras que la misma, promueve una integración cultural entre uruguayos y brasileños?

Para poder seleccionar los sujetos entrevistados se recurrió a la Secretaría de la Unipampa, la cual informó que fueron 21 alumnos los que ingresaron por la categoría "uruguayos fronterizos", de los cuales la mayoría (12) ingresaron en el 2012, después fue disminuyendo el ingreso de los mismos, 3 alumnos en el 2013, 4 alumnos en el 2015, y solo 2 en 2016. También otro dato interesante es que la mayoría de los ingresos (12) eligieron el curso de Letras de los cuales 8 aún están cursando y 4 abandonaron o pararon por un tiempo sus estudios. En el curso de Turismo se registraron 4 ingresos, de los cuales, solo uno 
permanece en la facultad, los restantes desistieron. El curso que tuvo solo un ingreso fue el de Producción y Política Cultural, el cual aún lo está cursando, no se presentaron alumnos en el curso de Historia.

De los datos obtenidos se tomó como criterio para la selección de los entrevistados, seleccionar un alumno que permanezca cursando y otro que haya desistido en los diferentes cursos como ser: Pedagogía, Turismo, Letras y Producción Cultural, siendo que en el Curso de Historia no hay uruguayos que ingresaron por esta modalidad. Considerando las diferentes percepciones que pueden tener estos alumnos. Siendo un total de seis alumnos los que fueron entrevistados, ya que en el curso de Producción Cultural solamente hay un alumno uruguayo fronterizo y el único matriculado en Turismo, no será entrevistado, por razones personales. Cabe destacar que los nombres de los entrevistados mencionados en este artículo son ficticios preservando de esta forma su privacidad e identidad.

Considerando los datos obtenidos se ha realizado un abordaje analítico, partiendo de las respuestas de los sujetos entrevistados, para poder reflexionar y articular lo manifestado por estos alumnos uruguayos fronterizos, sus diferentes percepciones acerca del tema en estudio, con los diferentes autores teóricos mencionados a lo largo de todo este trabajo académico.

\section{Las percepciones de los sujetos}

Para poder realizar el análisis de los diferentes actores entrevistados sobre la temática en estudio, debemos tener en cuenta que cada sujeto expone sus ideas vinculados a una determinada posición histórica, política y socio cultural. Cabe resaltar que las respuestas no sufrieron alteraciones en la sintaxis original, es decir, fueron transcritas de acuerdo con palabras textuales de los entrevistados.

En lo que respecta a la pregunta ¿consideras que existen o existieron elementos, factores o condicionantes que favorecieron o desfavorecieron tu integración cultural? Todos con excepción de dos entrevistados, colocan al idioma como un elemento que desfavorece la integración cultural. Andrea que desistió del curso de Turismo hizo referencia solamente al idioma como factor que impide la integración cultural, dice que "cuando se trataba de profesores que venían de otros estados de Brasil se hacia un poco dificultoso poderlos entender con la parte del idioma". Sandra que abandono el curso de Licenciatura en Pedagogía sostiene que la dificultad en el idioma la fue alejando de la facultad. Federico, alumno cursando Producción y Política Cultural también menciona al idioma como elemento que desfavorece la integración. "Yo no me crie con el portuñol, porque no soy de acá, hace 6 
años que vivo acá y es aprender una lengua que no es mi lengua materna tampoco es mi segunda lengua. Es aprenderla de cero". En sus palabras coloca al portuñol como un tercer idioma, porque él no se crio en la frontera, el portugués no es su lengua materna, y debe partir de cero, lo ve como barrera para poder relacionarse. "Siempre hay una barrera, inclusive para hacer trabajos, porque piensan que éste no habla bien el portugués". Ana Laura alumna del Curso de Licenciatura en Letras sostiene que "en relación al español era muy básico y el portugués que dan en la Unipampa supone que todos tienen la misma base para acompañar y tuve que recuperar esa base para acompañar, los primeros meses quise desistir". Fabricio ex alumno de Letras sostiene que el idioma no fue un elemento que desfavoreció debido a que los profesores siempre trataban de integrarlos. "Los docentes siempre trataban de preguntar si estábamos entendiendo, por el idioma más que nada y siempre fueron receptivos en ese sentido, porque a veces hablábamos mal, porque al no ser nativo en Brasil si bien conocemos el idioma, a veces nos confundíamos y todo y nunca hubo un problema con eso”. Sostiene además que la enseñanza del español en su curso favorecía la integración cultural cuando dice "sobre todo en algunas materias específicamente por el hecho de que hablara en español me favoreció, las asignaturas que tuviera que ver con el idioma”. También expone que las pruebas de ingreso para alumnos uruguayos fronterizos al ser ahora en español es un elemento que favorece la integración cultural. María alumna que está cursando Licenciatura en Pedagogía, manifiesta que ella no tuvo problemas con el idioma, solamente el acento propio del idioma es lo que la distinguía de los demás brasileños. "El sotaque, como ellos dicen, es notorio pero en si nunca tuve dificultades con el idioma, la lengua portuguesa”.

Se puede concluir a partir de los diversos relatos, que el idioma, es un factor que obstaculiza la integración cultural, que su incidencia es tan fuerte, que puede: promover la integración o por lo contrario llevar a la exclusión. La lengua es uno de los tantos elementos que componen la cultura, al considerar solo la existencia del idioma portugués y no del español en la mayoría de los cursos, no solo se está marcando la diferencia, sino que también se está promoviendo la identidad nacional, y se está desconociendo las historias, la existencia de ese otro. Como dice Couto (2012, p. 55).

Notamos que brasileiros e uruguaios marcam seus territórios identitários nacionais à medida que excluem ou ignoram o outro, a outra língua, as outras histórias. Esse processo de negação da língua também é um processo de produção de identidade nacional, de marcação da diferença, pois remete àquilo que simbolicamente identifica as pessoas com o lugar, ou que produzem sensação de pertencimento àquele ou a este lugar. 
Como otro elemento que desfavorece la integración cultural Sandra, ex aluna del Curso de Pedagogía, manifiesta las diferencias de los sistemas educativos.

Existe una diferencia grande acerca de cómo nosotros nos manejamos en el proceso educativo y como se dictan ahí. Nosotros, en el caso mío, más bien interpretamos la lectura y no volcamos al aula solo lo leído, sino lo que interpretas, y como que ahí tenias que hacer la devolución según tus colegas como estaba en el texto, habiendo más un aprendizaje de memoria. En realidad estaba extraña dentro de la facultad.

Se puede deducir a través de su relato, que lo cultural también puede estar reflejado en cómo se mire los procesos de enseñanza y de aprendizajes, y esto puede influir de cierta forma en la integración cultural. Ella lo ve como dos culturas distintas, con sistemas educativos diferentes, reflejado en los trabajos en grupo, donde su forma de estudio era diferente a la de sus compañeros, destacando tendencias diferentes, como ser: las tradicionalistas donde uno de los ejes principales era la memorización, y una tendencia más interaccionista cuyo enfoque apuntaría a la construcción e interpretación de hechos. Éste conjuntamente con otros factores, produce lo que ella le llama de "sentirse extraña en la facultad". Otro factor que Sandra menciona, que desfavorecía la integración cultural, es que existe una frontera demarcada por una línea, que separa más de lo que une y lo manifiesta diciendo que

cuando existían problemas en la frontera, en aula se podría haberlo visto como algo generalizado, pero no, siempre se lo veía del lado de Brasil o sea como que el problema siempre llegaba a la frontera, y no más. Uruguay no existía, nosotros no existíamos culturalmente.

Se puede ver, según ella, que la facultad no considera la región, esa frontera, no tiene en cuenta la existencia de los uruguayos que también son fronterizos, o sea, ella menciona el concepto de frontera como barrera, como límites entre países y entre ciudades. Podemos ver lo que Couto (2012) menciona que la frontera es un espacio de producción y marcación de identidades y diferencias. A partir del relato de la entrevistada, se percibe a la frontera en contraposición a lo que Gómez $(2011$, p.3) la definía como "espaço de hibridismo e de integração no contexto ideológico do mundo globalizado" Otro factor interesante que destaca la entrevistada, son los obstáculos, que en vez de integrar llevan a la exclusión, lo manifiesta diciendo "quizás la expectativa mía era demasiado, no me sentí acobijada, por lo contrario siempre habían obstáculos, una detención para hacer algo, no lograba el eslabón para poder continuar”. María, estudiante de Pedagogía, también destaca sentimientos de exclusión. 

e-ISSN 2016/Atual: 2525-7870 | e-ISSN 2015/2016: 2447-018X

No pensé que fuera tan chocante para la vista lo que es el alumno brasileño de pedagogía estar conviviendo en lo que es la educación al lado del uruguayo fronterizo. Yo de cierta forma intente integrarme, pero yo sentía el rechazo de cierta forma con una mirada, o sentía ¡ah la "castelhana!"(...), cosas sentía pero yo dejaba pasar porque ellos saben lo que hacen y ahí reflejan el profesor que van a ser.

Fabricio también en sus relatos, nos cuenta una anécdota, en la que expone que "habian algunos compañeros que creían que no se debería dar vacantes por ejemplo a extranjeros, en este caso uruguayos, ni tampoco a los indios, porque solo los brasileños deberian estudiar, pero ese es un hecho puntual y depende de lo que piense cada uno”.

A partir de estas expresiones, de estos sujetos entrevistados podemos ver las diferentes posiciones, tanto de alumnos uruguayos como de brasileños, las relaciones que se establecen, los sentimientos que afloran por la diversidad cultural que está latente en el aula, en espacios compartidos. Y que hace que se genere un cuestionamiento, acerca de cómo se está pensando el proceso de enseñanza y aprendizaje desde la diversidad, cuáles son las estrategias que se están usando para promover la integración, para que se fomente una educación intercultural como se expuso en las secciones anteriores de este trabajo académico, donde la valorización y el respeto por las diversidad de razas, géneros, culturas, sería un punto de partida.

Se puede ver en las palabras de Federico alumno de Producción y Política Cultural, que si se generan lazos entre las personas, si se fomenta las relaciones interpersonales se podría acercar un poco más a una visión integracionista.

Favorece la integración cultural los espacios de encuentro, los trabajos en grupos, el trabajar en común hace que se pueda compartir, he podido llevar a esos chiquilines que vinieron de lejos a Montevideo, y he podido irlos a ver lejos de Yaguarón. Las redes sociales son algo que integran mucho también, no existen los límites, las divisas, las fronteras, más allá de las diferencias lingüísticas.

Podemos ver en sus palabras lo que Londoño (1995, p.12) entiende por integración "como proceso que debe ser analizada en el marco de una dinámica que sobrepasa las fronteras nacionales e involucra el encuentro e intercambio entre múltiples sujetos".

En lo que respecta a la pregunta: ¿En tu trayectoria académica en la Unipampa, consideras que la misma promueve una integración cultural, entre uruguayos y brasileños? La mayoría de los sujetos entrevistados sostienen que la Unipampa no promueve la integración cultural entre brasileños y uruguayos. A continuación será explicitado en los diferentes relatos de los mismos.

Andrea, ex alumna del curso de Turismo, sostiene: "puede haber un intento en algunas disciplinas de hacer un acercamiento, pero creo que es un largo camino a recorrer 
como que faltan de repente en esa integración, programas, y especificar un poco más hacia lo que es un área fronteriza”.

Partiendo de sus palabras podemos ver que manifiesta la necesidad de programas, o sea, no es posible pensar en integración si no existen proyectos que promuevan y respalden esa integración cultural, y los mismos deben ser contextualizados, porque la facultad se encuentra en una región fronteriza. Este artículo en sus secciones considera diversos aspectos y en la sección que trata sobre qué se entiende por integración cultural, plantea sobre la necesidad de pensar la misma desde la educación, en una perspectiva de la interculturalidad, la cual se encuentra fundamentada en la diversidad.

Sandra, ex alumna de Pedagogía, hace referencia a la existencia de cupos y según ella "si existe cupos, no existe integración, me parece que es algo particular de ellos y dio la casualidad de vamos a mirar un poquito a la frontera pero en realidad no miran”. Federico, alumno del curso de Producción Cultural, también en su relato menciona que "la institución lo único que hace es colocar los lugares para uruguayos. Hoy hay siete lugares de cursos $X$ y nada más. Muchos docentes están parados desde un lugar inclusivo y de integrar, otros es tolerar que hayan uruguayos, no están parados en la inclusión”. También sostiene que:

no hay un lugar acá en que los uruguayos estén organizados por ejemplo en la UNILA en los diferentes cursos, hay una organización de uruguayos, y de otras nacionalidades, para llevar en una actividad elementos de otras culturas, por ejemplo en documentales, música, músicos y presentarlos a la comunidad académica.

Podemos ver según los entrevistados que la existencia de cupos es un limitante, en una facultad en territorio brasileño, donde la mayor parte son brasileños, pero al tener alumnos de diferentes estados de Brasil, de diferentes etnias y culturas y también uruguayos con sus culturas, nos muestra la necesidad de pensar en una integración, desde y para la diversidad cultural. Federico, también menciona la necesidad de organización y movilización por parte de los uruguayos, en el sentido de intentar proyectos o de alguna forma acercar e incluir su cultura. Aunque el hablar de integración cultural, según todo lo expuesto en este trabajo académico, va mucho más allá de la frontera, es hablar de políticas pensadas desde una perspectiva intercultural, que involucra a todos los sectores y actores de la universidad.

Ana Laura estudiante de Letras dice que ella no ve que se promueva integración.

El ingreso de uruguayos está disminuyendo, en realidad la facultad no hace mucho para promover la integración, ahora se ha hablado de ofrecer a los uruguayos un curso de portugués más básico, lo he charlado con chiquilinas que han entrado hace 2 años y han pensado en desistir. Cuando ingrese el español que enseñaban era el 
RELACult - Revista Latino-Americana de Estudos em Cultura e Sociedade

Revista Latinoamericana de Estudios en Cultura y Sociedad | Latin American Journal of Studies in Culture and Society

V. 02, Ed. Especial, dezembro, 2016, p. 225-246| periodicos.claec.org e-ISSN 2016/Atual: 2525-7870 | e-ISSN 2015/2016: 2447-018X

español de España, eso porque los profesores estudiaban allá, realizaban intercambios, era muy diferente no entendíamos muchas cosas, después con el ingreso de uruguayos los profesores se fueron adecuando y utilizando más el español de acá".

A partir de su relato podemos percibir que las dificultades, son obstáculos para la existencia de integración cultural, que conllevan a la desmotivación, abandono y exclusión. La no existencia de programas pensados para esta región lo manifiesta diciendo que los profesores enseñaban un español de España, que muy distante está, al idioma de una región de frontera, que tiene sus propias especificidades. El contacto, el convivir con los uruguayos fronterizos, permitió un acercamiento a otras realidades, a otras culturas.

María, estudiante de Pedagogía, sostiene que "integración entre personas mismo, no hay, no es sentarte en un evento y mirar ";ah que lindo como bailan!”, o “ique bonito poema!", no es tan así, tienes que intentar entrelazar a las personas para que realmente haya una integración cultural, y haya un intercambio de palabras y diálogo". O sea, no se logra la integración cultural, porque no es solo pensarla desde eventos, ella propone "establecer lazos, intercambio de palabras, diálogo". Aspectos ya mencionados durante la propuesta teórica que es la base de dicho trabajo, que se fundirían en una perspectiva intercultural de educación.

Fabricio, ex alumno de Letras, es el único que afirma que la Unipampa promueve la integración cultual, en sus argumentos dice que

si claro que si, tanto es así que no recuerdo bien si fue el año pasado o el otro año que hubo un evento, donde se incluyó lo cultural vinculado en la frontera, incluso trajeron a Fabián Severo, que es un escritor uruguayo de la frontera que presento sus poemas que tiene que ver con esa región de frontera.

Podemos ver que Fabricio, a diferencia de María, expresa que la integración se da a partir de la existencia de eventos que de cierta forma traen la cultura uruguaya y promueven intercambios a partir de dichos eventos.

A partir de los relatos, las diferentes voces dan a conocer sus percepciones, sus experiencias y nos muestran lo mucho que se relacionan sus visiones con todo lo discutido en este trabajo académico.

\section{Consideraciones Finales}

A lo largo del proceso y desarrollo de la temática en estudio, se pudo ver la complejidad de la misma. No fue fácil seleccionar los aspectos que serian fundamentales para 
poder cumplir con los objetivos propuestos, teniendo en cuenta, el reducido tiempo disponible y la limitada extensión del trabajo.

Para la elaboración de este trabajo se realizaron diversas lecturas, focalizando algunos aspectos, dejando de lado otros, estudiando diversos autores, aspectos éstos fundamentales para la comprensión del estudio en cuestión. Los objetivos propuestos fueron considerados en todo el desarrollo del trabajo académico, pudimos ver las diferentes percepciones de los sujetos entrevistados sobre el tema, constatando que la gran mayoría considera que la Unipampa no promueve una integración cultural como institución educativa, que muchas veces depende de cómo cada profesor desarrolla su clase. También desde su visión y experiencia, cada entrevistado dio a conocer elementos, factores que favorecen $o$ desfavorecen su integración cultural. Esto es muy importante, porque permite que se reflexione acerca de lo que se está haciendo y empezar a pensar, a discutir, como institución educativa, qué se podrá hacer para promover la integración en sus diferentes aspectos étnicos, sociales, culturales y demás. Este trabajo académico es solo un inicio, un llamado a la reflexión, que no se logra en solitario, que depende de todos los actores que pertenecen a la institución, de los gobiernos de los países como Brasil y Uruguay, de la existencia de políticas públicas y de diversos factores que pueden ser tratados en futuros trabajos académicos.

Pienso, a partir de todo lo estudiado, que la universidad por ser un espacio de elaboración y construcción de conocimiento, de relaciones entre diversidades étnicas, sociales y culturales debería ser el lugar propicio para la integración cultural, porque si no se estaría dejando espacio para la exclusión. En este sentido este trabajo sostiene que se necesita pensar y mirar a la educación desde una perspectiva intercultural para lograr que exista esa integración cultural. De esta forma la universidad pasaría a ser un espacio de encuentro, de diálogos y de intercambios, pero para que esto suceda, deben existir políticas públicas educativas que promuevan ese diálogo intercultural. Es decir donde no exista la legitimación de verdades únicas y de una única cultura hegemónica, sino que por el contrario se piense y se actúe desde y para la diversidad cultural, donde todos tienen los mismos derechos, las mismas oportunidades, donde las diferencias no solo son respetadas sino también reconocidas y valorizadas. A veces esto parece ser un poco lejano y para muchos utópico, pero se trató de demostrar en este trabajo, a través de ejemplificaciones de otras instituciones, que es posible.

Estamos en una universidad privilegiada, caracterizada por un contexto diverso, por la riqueza de una frontera, que necesita y debe ser pensada como puente de unión, de integración. Sabemos que existirá un largo camino que recorrer, que es difícil pero no imposible, que solo se logra lo que se quiere, cuando se es consciente y se lucha en colectivo. 


\section{Referencias}

CANCLÍNI, Néstor García. Culturas hibridas: estrategias para entrar y salir de la modernidad. Buenos Aires: Sudamericana, 1992.

CANDAU, Vera Maria.Direitos humanos, educação e interculturalidade:as tensões entre igualdade e diferença. Revista Brasileira de Educação v. 13 n. 37 jan./abr. 2008.

COUTO, Regina Célia do. O currículo como produtor de identidade e de diferença: efeitos na fronteira Brasil-Uruguay. Regina Célia do Couto; Orientador: Jarbas Santos Vieira. - Pelotas, 2012. 207f. Tese (Doutorado em Educação) - Programa de Pós-Graduação em EducaçãoUniversidade Federal de Pelotas.

FERNÁNDEZ, Daniela Tamara. Educación Superior en contextos multiculturales: un estudio de caso en La Universidade Federal da Integração Latino-americana - UNILA. Trabajo de Conclusión de Carrera de Graduación en Ciencias Políticas y Sociología - Sociedad, Estado y Política en América Latina - Universidade Federal da Integração Latino-americana, Foz do Iguazú, 2014.

GOVERNO FEDERAL (BRASIL). Ministério das Relações Exteriores; Fundação Alexandre Gusmão.

GOVERNO FEDERAL (BRASIL). Ministério da Educação. Secretaria de Educação Básica; REPÚBLICA DE ARGENTINA. Ministerio de Educación, Ciencia y Tecnología. Dirección Nacional de Cooperación Internacional Subsecretaría de Educación Básica. Escuelas de Frontera. Programa Escuelas Bilíngües de Frontera (PEBF) Brasilia, Buenos Aires. Octubre de 2007.

GOMEZ, M. L. A fronteira Brasil-Uruguai: o Mercosul, participação política e identidades sociais. DIPROSUL. 2011. Pelotas/RS.

HALL, S. Da diáspora: identidades e mediações culturais.Belo horizonte: Ed. UFMG, 2006.

LONDOÑO C. A. M. Los procesos de integración desde una perspectiva cultural. Revista Académica de la Federación Latinoamericana de Facultades de Comunicación Social. Diálogos de la comunicación No 79, Enero- Junio. 2010.

MACHADO, Cristina Gomes. Multiculturalismo: muito além da riqueza e da diferença. Rio de Janeiro: DP\&A, 2002.

MAZZEI, Enrique. Fronteras que nos unen y límites que nos separa. Melo, Cerro Largo, Uruguay. 2012.

MELLO, Luis Gonzaga de. Antropología cultural: Iniciación, teoría e temas.18 ed.Petrópolis: Vozes, 2011.

MERCOSUR. Protocolo de Integración Cultural del Mercosur. DEC No 11/96. Fortaleza. 17/12/1996. 

e-ISSN 2016/Atual: 2525-7870 | e-ISSN 2015/2016: 2447-018X

MINAYO, Maria Cecília de Souza (org.). Pesquisa Social. Teoria, método e criatividade. 18 ed. Petrópolis: Vozes, 2001.

PUCCI, Adriano Silva. O estatuto da fronteira Brasil-Uruguai. Brasília: FUNAG, 2010.

PRESIDÊNCIA DA REPÚBLICA. Decreto Nº 5.105. 14de Junho de 2004.

PRESIDENCIA PRO TEMPORE URUGUAY. MERCOSUR EDUCATIVO. Que es el Sector Educativo del Mercosur. 2016.

RICOBOM, Gisele. La integración latinoamericana y el diálogo intercultural: nuevas perspectivas desde la universidad. Anais do XIX Encontro Nacional do CONPEDI. Fortaleza/CE (09, 10, 11 e 12 de Junho de 2010).

RIZZON, Carlos Garcia. Outras geografias em literaturas de fronteira. Volume 6, Número 2, p. 114- 124, jul./dez. 2012. Instituto de Geociências, Programa de Pós-Graduação em Geografia, Universidade Federal do Rio Grande do Sul, Porto Alegre, RS, Brasil.

SANTOS, Boaventura de Souza. A gramática do tempo: para uma nova cultura política. São Paulo: Cortez, 2006.

SILVA, Tomaz Tadeu. A produção social da identidade e da diferença. In: SILVA, Tomaz Tadeu (Org.) Identidade e diferença: a perspectiva dos estudos culturais. Petrópolis, RJ: Vozes, 2000.

WALSH, Catherine. La educación intercultural en la educación. Perú: Ministerio de Educación, 2001.

Recursos electrónicos

Portal Unipampa - www.unipampa.edu.br

Governo Federal - www.planalto.gov.br 